\title{
Ethnic differences in general practitioner consultations
}

\author{
R Balarajan, P Yuen, V Soni Raleigh
}

Abstract

Objective-To examine the levels of general practitioner consultations among the different ethnic groups resident in Britain.

Design-The study was based on the British general household surveys of 1983-5 and included 63966 people aged 0-64. Odds ratios were derived for consultation by ethnic group by using logistic regression analysis adjusting for age and socioeconomic group.

Setting-The results relate to people living in private households in England, Scotland, and Wales.

Results-After adjustment for age and socioeconomic class, consultation among adults aged 16-64 was highest among people of Pakistani origin with odds ratios of 2.82 (95\% confidence interval 1.86 to 4.28$)$ for men and $1.85(1.22$ to 2.81$)$ for women. Significantly higher consultations were also seen for men of West Indian and Indian origin (odds ratios 1.65 and 1.53 respectively). Ethnic differences were greatest at ages 45-64, when consultation rates in people of Pakistani, Indian, and West Indian origin were much higher in both sexes compared with white people.

Conclusions-The ethnic composition of inner cities is likely to influence the workload and case mix of general practitioners working in these areas.

\section{Introduction}

Patterns of mortality are known to vary between ethnic groups in Britain. ${ }^{12}$ Studies based on hospital data have also reported on ethnic differences in morbidity, especially among people originating from the Indian subcontinent and the West Indies. ${ }^{3+}$ Reports on ethnic differences in morbidity encountered in general practice are, however, limited. We investigated consultations with general practitioners among the various communities living in Britain by using data from the British general household surveys.

\section{Subjects and methods}

The general household survey is a probability sample survey of the population living in private households in Great Britain and is conducted annually by the Office of Population Censuses and Surveys. It covers some 25000 people from 10000 households, and data are collected on a wide range of economic and social variables such as population, housing, employment, education, and health. We used data from the general household surveys of $1983-5,,^{5-7}$ the latest years that included questions on ethnic origin. Respondents were asked to identify their ethnic group from the following categories: white, West Indian, Indian, Pakistani, Bangladeshi, Chinese, African, Arab, and mixed or other. We have presented the results for white people, West Indians, Indians, and Pakistanis but not those for other ethnic groups because of the small numbers.

The analysis was based on responses to questions about consultations (in the surgery or home or over the telephone) with a general practitioner over the preceding 14 days. The study was confined to respondents aged under 65 years as there were insufficient numbers of elderly patients in some ethnic groups. We examined consultation rates by age, sex, and ethnic group. We also modelled the probability of consulting a general practitioner by using the method of logistic regression ${ }^{8}$ allowing for age and socioeconomic group as these factors are known to influence consultation rates. ${ }^{9}$ In the model the ages were grouped as follows: $<1,1-4$, and then 10 year age groups up to 64 . The socioeconomic groups were classified into 1 , professional and managerial; 2, intermediate, junior non-manual workers; 3 , skilled manual workers; and 4 , semiskilled or unskilled manual workers. Adjusted odds ratios were calculated separately for males and females for ages 0-15 and 16-64. In the case of women and children the socioeconomic group of the head of household was used. When appropriate $95 \%$ confidence intervals were calculated.

\section{Results}

There were 63966 people in the study sample and table I shows their distribution by age and ethnic group for males and females. Although age distributions did not differ significantly between white people and West Indians, Indians and Pakistanis showed differences in age structure. Table II shows consultation rates for males and females by age and ethnic group. Among white males consultation was highest at ages $0-15$ followed by 45-64. In contrast, Indian, Pakistani, and West Indian males consulted most at ages 45-64 followed by $0-15$ (fig 1 ). Consultation rates in white women were highest at ages 16-44 followed by 45-64. The pattern was reversed in Indian, Pakistani, and West Indian women, who consulted doctors more at ages 45-64 than in the childbearing ages (fig 2). In both sexes the variation in consultation rates by age was much greater among Indians, Pakistanis, and West Indians than among white people.

Among Pakistanis the consultation rate for boys aged $0-15$ was $60 \%$ higher than that for girls, whereas other groups did not show major differences by sex of child. Rates among boys were highest among
University of Surrey,

Guildford, Surrey

GU2 5XH

R Balarajan, FFCM, professor and director

P Yuen, MSc, research fellow V Soni Raleigh, PHD, senior research fellow

Correspondence to:

Professor Balarajan.

Br.Med f 1989:299:958-60
TABLE I-Distribution (percentage) of study sample by age, sex, and ethnic origin

\begin{tabular}{|c|c|c|c|c|c|c|c|c|}
\hline \multirow[b]{2}{*}{ Ethnic origin } & \multicolumn{4}{|c|}{ Males } & \multicolumn{4}{|c|}{ Females } \\
\hline & $0-15$ & $16-44$ & $45-64$ & $0-64$ & $0-15$ & $16-44$ & $45-64$ & $0-64$ \\
\hline White & $8220(27)$ & $14639(47)$ & $7965(26)$ & 30824 & $7596(25)$ & $14870(48)$ & $8484(27)$ & 30950 \\
\hline Indian & $196(36)$ & $257(48)$ & $85(16)$ & 538 & $170(33)$ & $267(53)$ & $70(14)$ & 507 \\
\hline Pakistani & $108(46)$ & $88(37)$ & $39(17)$ & 235 & $107(49)$ & $92(42)$ & $20(9)$ & 219 \\
\hline West Indian & $96(28)$ & $163(48)$ & $84(24)$ & 343 & $96(27)$ & $186(53)$ & $68(20)$ & 350 \\
\hline
\end{tabular}

*Source: general household surveys 1983-5. 
TABLE II -Consultation rates per 1000 by age, sex, and ethnic origin with actual numbers in parentheses

\begin{tabular}{lccccccc}
\hline & \multicolumn{3}{c}{ Males } & & \multicolumn{3}{c}{ Females } \\
\cline { 2 - 3 } \cline { 7 - 8 } Ethnic origin & $0-15$ & $16-44$ & $45-64$ & & $0-15$ & $16-44$ & $45-64$ \\
\hline White & $137(1123)$ & $85(1246)$ & $129(1030)$ & & $139(1056)$ & $169(2507)$ & $153(1294)$ \\
Indian & $133(26)$ & $97(25)$ & $259(22)$ & & $135(23)$ & $191(51)$ & $257(18)$ \\
Pakistani & $194(21)$ & $193(17)$ & $333(13)$ & & $121(13)$ & $250(23)$ & $400(8)$ \\
West Indian & $135(13)$ & $104(17)$ & $238(20)$ & & $135(13)$ & $177(33)$ & $221(15)$ \\
\hline
\end{tabular}

*Source: general household survers, $1983-5$.

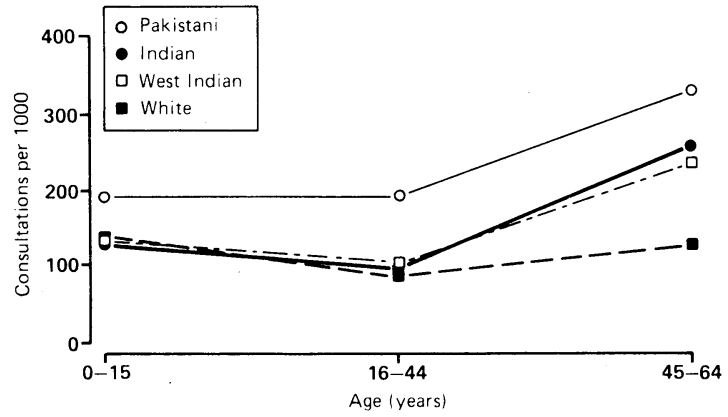

FIG 1 -Rate of consultations with general practitioners by ethnic origin for males aged 0-64 (source: general household surveys 1983-5)

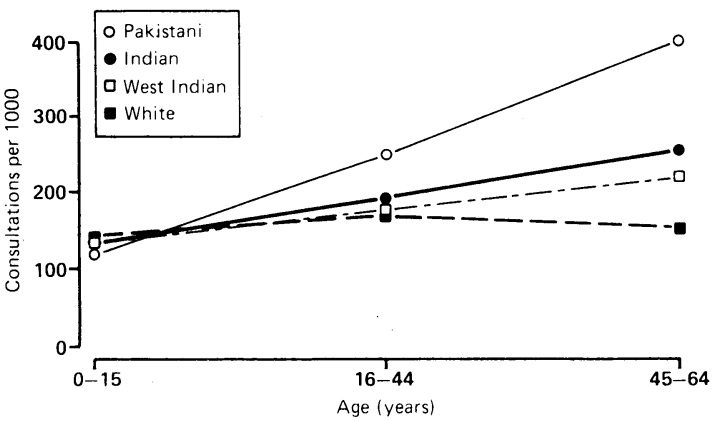

FIG $2-$ Rate of consultations with general practitioners by ethnic origin for females aged 0-64 (source: general household survevs 1983-5)

Pakistanis (194/1000), with Indians and West Indians showing little variation from white people (137/1000). Ethnic differences in consultation rates among girls were much smaller, the rate being lowest in Pakistanis (121/1000). At ages 16-44 Pakistani men consulted doctors more than twice as often as white men. Rates in Indian and West Indian men were similar and showed a small excess over white men. In women aged 16-44 again rates were highest in Pakistanis (250/1000), followed by Indians (191/1000), the rates in white and West Indian women being similar. Ethnic differences in consultation rates were greatest at ages 45-64, with consultation rates in Indians, Pakistanis, and West Indians being much higher in both sexes than those seen among white people. Rates in Pakistani and Indian men at these ages were more than twice those of white men, and almost twice in West Indians (fig l), whereas the rates in Pakistani, Indian, and West Indian women were $161 \%, 68 \%$, and $44 \%$ higher respectively than in white women (fig 2).

Table III shows the consultation ratios adjusted for age and socioeconomic group for boys and girls aged 0 15. There were no significant differences between the ethnic groups in either sex, though the ratio was high in Pakistani boys (odds ratio $1 \cdot 44$ ). Table IV shows the consultation ratios adjusted for age and socioeconomic group among men and women aged 16-64. In men the odds ratio was highest in Pakistanis (odds ratio 2.82, $95 \%$ confidence interval 1.86 to $4 \cdot 28$ ) followed by West Indians $(1.65,1 \cdot 16$ to $2 \cdot 34)$ and Indians $(1.53,1 \cdot 12$ to $2 \cdot 09)$. In women only Pakistanis showed a significant excess $(1 \cdot 85,1 \cdot 22$ to $2 \cdot 81)$, with a raised odds ratio also in Indians $(1 \cdot 23,0.94$ to 1.61$)$ and West Indians $(1 \cdot 17$, 0.85 to $1 \cdot 60)$.

\section{Discussion}

The general household survey provides a unique opportunity to examine health issues in relation to social, demographic, and economic variables based on a large representative sample of people living in private households in Great Britain. We aggregated data for the years 1983-5 to examine general practitioner consultation rates by ethnic origin among 63966 respondents distributed across Greater London and the eight' standard regions in England, Scotland, and Wales. The material presented here relates to ethnic groups with sufficient observations for the analysis undertaken. The general household survey is conducted through a detailed interview by trained interviewers who are briefed extensively to minimise differential responses from the various groups. The detailed guidelines to interviewers on the definition and classification of consultations should also reduce the possibility of error in the responses.

Our findings showed significant ethnic differences in consultations with general practitioners after adjustment for age and socioeconomic group. Of particular importance were the high numbers of consultations among men and women of Pakistani origin, these being almost three times and double those in white men and women respectively. Men of West Indian and Indian origin showed a smaller but none the less significant excess in consultation rates of $65 \%$ and $53 \%$ respectively. Rates were raised also in West Indian and Indian women, though these results were not significant. Among children aged 0-15 consultation rates were raised only in boys of Pakistani origin, who showed a $44 \%$ excess over white boys of corresponding ages. The examination of population based ethnic differences in mortality and morbidity in England and Wales has been constrained by the lack of appropriate population denominators, as ethnic origin is not recorded in the census. Analyses based on country of birth as a proxy for ethnic origin show a somewhat higher overall mortality in women born in the Indian subcontinent over that prevalent in England and Wales, with no differences in men.' Cause specific mortality, on the other hand, varies in people of Indian origin with high mortality from cardiovascular diseases, diabetes, and genitourinary diseases and low mortality from cancer. ${ }^{12}$ Morbidity patterns among Asians show similar variations.

Our findings, based on a national population sample

TABLE III-Odds ratios for consultations with general practitioner adjusted for age and socioeconomic group of head of household for patients aged $0-15^{\star}$

\begin{tabular}{lccrcr}
\hline & \multicolumn{2}{c}{ Males } & & \multicolumn{2}{c}{ Females } \\
\cline { 2 - 3 } \cline { 5 - 6 } Ethnic origin & $\begin{array}{c}\text { Odds } \\
\text { ratio }\end{array}$ & $\begin{array}{c}95 \% \text { Confidence } \\
\text { interval }\end{array}$ & & $\begin{array}{c}\text { Odds } \\
\text { ratio }\end{array}$ & $\begin{array}{c}95 \% \text { Confidence } \\
\text { interval }\end{array}$ \\
\hline White & 1.00 & & & 1.00 & \\
Indian & 0.91 & 0.60 to 1.40 & & 0.94 & 0.60 to 1.47 \\
Pakistani & 1.4 & 0.88 to 2.34 & & 0.78 & 0.43 to 1.41 \\
West Indian & 1.00 & 0.55 to 1.81 & & 0.97 & 0.53 to 1.77 \\
\hline
\end{tabular}

* Source: general household survers 1983-5.

TABLE IV-Odds ratios for consultation with a general practitione adjusted for age and socioeconomic group for men and age and socioeconomic group of head of household for women for patients aged $16-64^{\star}$

\begin{tabular}{lccccc}
\hline & \multicolumn{2}{c}{ Men } & \multicolumn{2}{c}{ Women } \\
\cline { 2 - 5 } \cline { 5 - 6 } Ethnic origin & $\begin{array}{c}\text { Odds } \\
\text { ratio }\end{array}$ & $\begin{array}{c}95 \% \text { Confidence } \\
\text { interval }\end{array}$ & $\begin{array}{c}\text { Odds } \\
\text { ratio }\end{array}$ & $\begin{array}{c}95 \% \text { Confidence } \\
\text { interval }\end{array}$ \\
\hline White & 1.00 & & 1.00 & \\
Indian & 1.53 & 1.12 to 2.09 & 1.23 & 0.94 to 1.61 \\
Pakistani & 2.82 & 1.86 to 4.28 & 1.85 & 1.22 to 2.81 \\
West Indian & 1.65 & 1.16 to 2.34 & 1.17 & 0.85 to 1.60
\end{tabular}

*Source: general household survers $1983-5$ 
with no numerator or denominator bias, show some - significant differences in the numbers of consultations with general practitioners among the Asian populations living in Britain. To what extent these differences reflect true morbidity, varying thresholds and perceptions of illness, or differential uptake of services are questions that we cannot answer. A study in the west midlands, showing that two thirds of Asians were registered with a general practitioner of Asian origin, concluded that the higher consultation rates seen in Asians related to genuine physical need. ${ }^{10}$ The study also noted that white people were more likely than those from ethnic minorities to bypass the general practitioner and use hospital outpatient or emergency services. A survey of ethnic differences in certified sickness absence showed that spells of absence and days lost were almost double in Asians compared with white people, though sickness absence cannot be regarded as an objective measure of morbidity. " Chronic conditions such as hypertension, heart disease, stroke, and diabetes are more common in Asians than in the indigenous population, and possibly our finding of higher consultation rates among Asians at ages 45-64 reflects this.

A significant finding of this study was the absence of higher consultation rates among Indian children and Pakistani girls, compared with the higher rate seen in Pakistani boys, especially when the higher perinatal mortality in Asian infants generally ${ }^{12}$ and postneonatal mortality in Pakistani infants $\mathrm{s}^{13}$ are considered. In the childbearing ages (16-44) consultation rates for Pakistani women were $48 \%$ higher than those for white women. Poor outcome in pregnancy and higher infant mortality in Pakistanis have been attributed among other reasons to poor antenatal attendance. ${ }^{1+}$ Paradoxically our findings showed higher consultation rates among Pakistani women of childbearing ages, though this could reflect their higher fertility compared with other groups. ${ }^{15}$ Although our study is limited in explaining issues relating to antenatal care, it is reassuring to see a considerably greater interaction of this group with general practitioners. Further studies to investigate the context in which these consultations take place, their content, and the outcome would contribute to the provision of better care for women of childbearing ages in this community.

Levels of consultations with general practitioners in West Indian women and children did not differ significantly from those in white people, though West Indian men showed a $65 \%$ excess. In contrast, mortality is lower in West Indian men but raised in West Indian women.' Hospital based studies have also shown higher incidences of some chronic diseases such as diabetes, hypertension, and stroke among West Indians, but again the excess is greater in women than in men. ${ }^{+}$This raises the need to investigate the causes underlying the differences observed in this study in the consultation rates of West Indian men and women.

Our findings showed considerably higher consultation rates with general practitioners in Pakistani adults and in Indian and West Indian men. Possibly, morbidity is contributory to this pattern of high consultations, especially among the Pakistani population. It is, however, encouraging to see the degree of access that these communities have to primary care, making it feasible for the NHS to take positive initiatives to deal with the specific needs of these communities. On the other hand, general practitioners working in inner cities, where a large proportion of people from ethnic minorities live, will be faced with not only a different case load but possibly also a different case mix, considerations that should influence the allocation of budgets and support services.

1 Office of Population Censuses and Survevs. Immigrant mortality in England and Wales 1970-78: causes of death by country of birth. London: HMSO, 1984. (Studies on Medical and Population Subjects, No 47.)

2 Balarajan R, Bulusu L, Adelstein AM, Shukla V. Patterns of mortality among migrants to England and Wales from the Indian subcontinent. Br Med $\mathcal{F}$ 1984;289:1185-7.

3 Donaldson LJ, Taylor JB. Patterns of Asian and non-Asian morbidity in hospitals. Br.Med f 1983;286:949-51

+ Cruickshank JK, Beevers DG, Osbourne VL, Haynes RA, Corlett JCR, Selby S. Heart attack, stroke, diabetes, and hypertension in West Indians, Asians, and whites in Birmingham, England. Br Med F 1980;281:1108.

5 Office of Population Censuses and Surveys. General household survey 1983. London: HMSO, 1985.

6 Office of Population Censuses and Surveys. General household survey 1984. London: HMSO, 1986

7 Office of Population Censuses and Surveys. General household survey 1985. London: HMSO, 1987.

8 Cox DR. Analysis of binary data. London: Chapman and Hall, 1972.

9 Balarajan P, Yuen P, Machin D. Socioeconomic differentials in the uptake of medical care in Great Britain. F Epidemiol Community Health 1987;41:196-9.

10 Johnson MRD, Cross M. Cardew SA. Inner-city residents, ethnic minorities and primary health care. Postgrad Med $\mathcal{F}$ 1983;59:664-7.

11 Baker CC, Pocock SJ. Ethnic differences in certified sickness absence. Br $\mathcal{I}$ Ind Med 1982;39:277-82.

12 Balarajan R, Botting B. Perinatal mortality in England and Wales: variations by mother's country of birth. Health Trends (in press).

13 Balarajan R, Soni Raleigh V, Botting B. Sudden infant death syndrome and postneonatal mortality in immigrants in England and Wales. $\mathrm{Br}$ Med $\mathcal{F}$ 1989;298:716-20.

14 Lumb KM, Congdon PJ, Lealman GT. A comparative review of Asian and British-born maternity patients in Bradford 1974-78. F Epidemiol Community Health 1981;35:106-9.

15 Office of Population Censuses and Surveys. Birth statistics 1986. London: HMSO, 1986. (Series FM I No 15.)

(Accepted 22 August 1989)

\section{ONE HUNDRED YEARS AGO}

We are at a period of the year when most town residents who can afford it are thinking with varied feelings about the summer holiday that they wish to take or have to undergo. Perhaps the most interesting type of holidaymaker is the true tourist - that is to say, the man who spends his vacation going about from place to place. The tourist class includes young men who go touring because they love exercise and novelty, and men of mature years who get depressed in lodgings at the seaside, and do not care for the habits of the public who throng to inland "waters." The elder tourist generally finds a tour far better as a remedy against professional fatigue and anxiety than a wearisome, sham repose for three weeks or over in a dull wateringplace properly suited for children. The tourist proper, when in congenial company or in his own company, follows his tastes; we put aside unfortunate men who tire themselves out feasting in Paris, or clambering over mountains in the company of younger companions who like those forms of relaxation, and we likewise dismiss from the true tourist class young gentlemen who travel with elder companions versed in old masters and archæology. Such unhappy men are victims, not tourists; their journey is a penance, not a relaxation. As for the touring Briton who hurries on as far as possible for his money, he enjoys himself after his fashion, and, so far, his tour does him good. The advantage of a good walking tour in the country or abroad is self-evident in the case of young men who will not exhaust themselves, and in respect to elder men still vigorous and endowed with prudence. Great, undoubtedly great, is the benefit of those more intellectual excursions so often undertaken by English gentlemen. Few pleasures are purer or more wholesome than a ramble through cathedral towns and cities, where architecture and historical associations can delight the mind fatigued by monotonous or absorbing intellectual work. Such men are often held up to ridicule; they are reminded that the country is the place for a holiday. This reminder includes a theory true in the main, but liable to misapplication; for such men have often lost the power of enjoying the country. Place one, or even a congenial brace, of these gentlemen for a fortnight in a secluded pastoral district, and he or they will soon become depressed and think of business too much, or possibly eat, drink, or smoke to excess. The first requisite in the tourist who can afford time and money is that he should follow his tastes. (British Medical Fournal 1889;ii:202) 